\title{
Trans-Zeatin attenuates ultraviolet induced down-regulation of aquaporin-3 in cultured human skin keratinocytes
}

\author{
CHAO JI $^{1 *}$, YANLI YANG ${ }^{2 *}$, BO YANG ${ }^{3}$, JIPING XIA ${ }^{1}$, WEILING SUN ${ }^{1}$, ZHONGLAN SU $^{1}$, LITING YU ${ }^{1}$, \\ SHIJUN SHAN ${ }^{4}$, SHAOHENG HE$^{5}, \mathrm{LEI} \mathrm{CHENG}^{2}, \mathrm{YINSHENG} \mathrm{WAN}^{6}$ and $\mathrm{ZHIGANG} \mathrm{BI}^{7}$ \\ Departments of ${ }^{1}$ Dermatology; ${ }^{2}$ Department Otolaryngology, the First Affiliated Hospital of Nanjing Medical University, \\ Nanjing 210029, Jiangsu; ${ }^{3}$ Department of Dermatology, Huashan Hospital, Fudan University, Shanghai 200040; \\ ${ }^{4}$ Department of Dermatology, Tianjin Medical University General Hospital, Tianjin 300052; ${ }^{5}$ Clinical Experiment \\ Center, the First Affiliated Hospital of Nanjing Medical University, Nanjing 210029, Jiangsu, P.R. China; \\ ${ }^{6}$ Department of Biology, Providence College, Providence, RI 02918, USA; ${ }^{7}$ Department of Dermatology, \\ the Affiliated BenQ Hospital of Nanjing Medical University, Nanjing 210019, Jiangsu, P.R. China
}

Received January 21, 2010; Accepted March 1, 2010

DOI: 10.3892/ijmm_00000460

\begin{abstract}
Solar ultraviolet (UV) irradiation is one of the most significant extrinsic factors contributing to skin photoaging. One major characteristic of photoaging induced by UV is water loss of the skin. Water movement across the plasma membrane can occur via two pathways: by diffusion through the lipid bilayer and by membrane-inserted water channels (aquaporins). In this study we demonstrate that UV induces aquaporin-3 (AQP3) downregulation in cultured keratinocytes (HaCaT cells). PD98059 and U0126, MEK/ERK inhibitors, inhibit UV-induced AQP3 loss. Trans-Zeatin (tZ), which alone induces AQP3 expression, attenuates UV-induced loss of AQP3. We found that $t Z$ inhibits UV-induced MEK/ERK activation; the latter serves as the key signal pathway mediating UV-induced AQP3 loss. Using specific AQP3 siRNA knockdown, we found AQP3 is involved in wound healing in human skin keratinocytes. Loss-of-AQP3-mediated delayed wound healing in UV-radiated skin keratinocytes is attenuated by $\mathrm{tZ}$ pretreatment. $\mathrm{tZ}$ pretreatment also attenuates $\mathrm{UV}$-induced decreased water permeability in $\mathrm{HaCaT}$ cells. We concluded that UV radiation downregulates AQP3 in HaCaT cells. $\mathrm{MEK} / \mathrm{ERK}$ activation is involved in this process. $\mathrm{tZ}$ treatment attenuates UV-induced AQP3 loss, in vitro wound healing
\end{abstract}

Correspondence to: Dr Zhigang Bi, Department of Dermatology, the Affiliated BenQ Hospital of Nanjing Medical University, 71 Hexi Avenue, Jianye District, Nanjing 210029, Jiangsu, P.R. China E-mail: eltonbibenqhospital@yahoo.com.cn

Dr Bo Yang, Department of Dermatology, Huashan Hospital, Fudan University, Shanghai 200040, P.R. China

E-mail: deryean@yahoo.com.cn

*Contributed equally

Key words: ultraviolet, aquaporin-3, trans-Zeatin, keratinocytes, wound healing, water permeability delay and water permeability decrease. This work provides a new explanation for the anti-photoaging potential of $\mathrm{tZ}$.

\section{Introduction}

Skin aging is a degenerative process whereby alterations from the passage of time (chronological/intrinsic aging) are superimposed with effects produced by environmental factors (e.g., sun, heat, pollution, and smoking). Among the extrinsic factors, solar ultraviolet (UV) irradiation is the most significant, and consequently the most studied. Solar UV light reaching earth comprises UVA (320-400 nm wavelength) and UVB (280$320 \mathrm{~nm}$ avelength). These two UV wavelengths are distinguished by their penetration properties $(1,2)$. UVB radiation reaches the upper part of the epidermis, a lesser extent of it, while UVA radiation penetrates more deeply into human skin $(2,3)$. However, although showing obvious differences, both UVA and UVB irradiations are responsible for the numerous adverse biological effects on human skin, including sunburn, immunosuppression, as well as long-term consequences such as skin cancers and premature skin aging (photoaging) $(4,5)$.

One major characteristic of photoaging is water loss of the skin. After exposure to UV, the skin may become dry and scaly. The deficient water conditions after exposure to UVB can damage the function of the stratum corneum, such as wrinkle formation and delayed wound healing $(6,7)$. Water movement across the plasma membrane can occur via two pathways: by diffusion through the lipid bilayer (8) and by membrane-inserted water channels (aquaporins; AQPs) (9-11). AQPs are a family of small ( $\sim 30 \mathrm{kDa} /$ monomer), hydrophobic, integral membrane proteins that are expressed widely in the animal and plant kingdoms, with 13 members having thus far been identified in mammals $(12,13)$. AQPs are expressed in various epithelia and endothelia involved in fluid transport, as well as in cell types that are originally not thought to carry out fluid transport, such as aquaporin-3 (AQP3) expression in the basal layer of keratinocytes in mammalian skin $(9,13)$, however, the functions of AQP3 in human skin keratinocytes 
remain to be further elucidated. Studies have demonstrated impaired stratum corneum hydration and delayed wound healing in AQP3-null mice as well as cultured skin cells (14-16). Previous works demonstrate that UV induces AQP3 downregulation in both skin keratinocytes (HaCaT cells) and skin fibroblasts, which leads to skin dehydration and delayed wound healing response in vitro $(17,18)$. All-trans retinoid acid, a well studied anti-skin aging agent, reduces UV-induced wound healing delay and water loss by inhibiting AQP3 degradation (17).

Zeatin, purified from zea mays, is a cytokinin plant growth factor (19). It has two forms, trans and cis. The activity of zeatin is attributed to its more stable trans form (20). Zeatin is one of the most widely studied cytokinins with growth modulatory and anti-senescence effects in plants (21). Considerable evidence has demonstrated that Zeatin possesses a variety of biological activities, such as anti-apoptotic efficacy, anti-oxidative activity, youth preserving and anti-aging effects on the human system (21). Our previous study has shown that trans-Zeatin (tZ) inhibits UVB-induced MMP-1 expression, which may be mediated by the inhibition of ERK, JNK and p38 MAPK signaling pathways in human skin fibroblasts. $t Z$ might be considered as a potential agent for the management of skin photoaging (16). However, whether and how AQP3, the water channel in skin, is involved in this protective effect has not yet been studied.

Given that UV radiation induces human skin dehydration and skin photoaging, and that AQP3 water channel plays an important role in skin physiology such as hydration and wound healing, we undertook this study to investigate whether $\mathrm{tZ}$ treatment has any protective effects against UV-induced AQP3 degradation or skin cell dehydration. We found that $t Z$ treatment, which alone upregulates AQP3 expression, attenuates UV-induced loss of AQP3 as well as loss-ofAQP3-mediated wound healing delay and water permeability decrease. Investigating the mechanisms, we found that inhibition of MEK/ERK activation is involved in $\mathrm{tZ}$ 's protective effects against UV-induced loss of AQP3. This finding provides novel insight into the mechanisms of tZ's protective effects against UV-induced photoaging.

\section{Materials and methods}

UV light apparatus. As previously reported (22), UV-irradiation apparatus used in this study consisted of four F36T12 EREVHO UV tubes. A Kodacel TA401/407 filter was mounted $4 \mathrm{~cm}$ in front of the tubes to remove wavelengths $<290 \mathrm{~nm}$. Irradiation intensity was monitored using an IL443 phototherapy radiometer and a SED240/UV/W photodetector. Before UV irradiation, cells were washed with $1 \mathrm{ml}$ PBS buffer and then changed to $0.5 \mathrm{ml}$ PBS (pre-warmed) in each well. Cells were irradiated at the desired intensity without plastic dish lid. After UV irradiation, cells were returned to incubation in basal medium with treatments for various times prior to harvest.

Chemicals and reagents. Rabbit anti-AQP3 was obtained from Chemicon (14), (Temecula, CA), rabbit anti-phospho-MEK, rabbit anti-MEK, rabbit anti-phospho-ERK and rabbit antiERK were obtained from Cell Signaling Technology (Danvers, MA). Goat anti-rabbit IgG-HRP and goat anti-mouse IgG-HRP antibody were received from Santa Cruz Biotechnology (Santa Cruz, CA). Monoclonal mouse anti- $\beta$-actin and $\mathrm{tZ}$ were obtained from Sigma (China). PD153035, AG 1478, U0126, LY294002, PD 98059, JNKi and SB 203580 from CalbioChem (San Diego, CA).

Cell culture. As described previously $(14,22)$, spontaneously immortalized human keratinocytes (HaCaT cells) were maintained in a DMEM medium (Sigma, St. Louis, MO) supplemented with a $10 \%$ fetal bovine serum (Invitrogen, Carlsbad, CA), penicillin/streptomycin (1:100, Sigma) and $4 \mathrm{mM}$ L-glutamine (Sigma), in a $\mathrm{CO}_{2}$ incubator at $37^{\circ} \mathrm{C}$. For Western blotting, cells were reseeded in 6-well plates at a density of $0.5 \times 10^{6}$ cells $/ \mathrm{ml}$ with fresh complete culture medium.

Western blot analysis. As reported previously (22), cultured human skin keratinocytes with and without treatment were washed with cold PBS and harvested by scraping into $100 \mu 1$ of RIPA buffer. Cell lysates were incubated in $4^{\circ} \mathrm{C}$ for $30 \mathrm{~min}$. Proteins $(20 \mu \mathrm{g})$ were denatured in 5x SDS-PAGE sample buffer for $5 \mathrm{~min}$ at $95^{\circ} \mathrm{C}$. Proteins were separated by 10 or $12 \%$ SDS-PAGE and transferred onto PVDF membrane (Millipore, Bedford, MA). Nonspecific binding was blocked with $10 \%$ dry milk in TBST for $1 \mathrm{~h}$ at room temperature. After blocking, membranes were incubated with specific antibodies in dilution buffer (2\% BSA in TBS) overnight at $4^{\circ} \mathrm{C}$. Blots were incubated with horseradish peroxidaseconjugated anti-rabbit or anti-mouse $\mathrm{IgG}$ at appropriate dilutions and room temperature for $1 \mathrm{~h}$. Antibody binding was detected using enhanced chemiluminescence (ECL) detection system (Amersham Biosciences) following the manufacturer's instructions and visualized by autoradiography with Hyperfilm.

In vitro wound healing ('scratch') assay. As described before (14), twelve-well plates were precoated with polylysine (30 $\mu \mathrm{g} / \mathrm{ml})$, followed by further BSA blocking. A sufficient number of serum-starved $\mathrm{HaCaT}$ cells were plated, so that they became confluent in the wells immediately after attachment (1-2 h). Same area of each well is then displaced by scratching a line through the layer with a needle. Floating cells were removed by PBS washing 3 times. Media contained $0.2 \%$ FBS without treatment for $36 \mathrm{~h}$. Mitomycin $\mathrm{C}(10 \mu \mathrm{g} / \mathrm{ml})$ was always included in the media to prevent cell proliferation. Ten representative images of the scratched areas under each condition were photographed. To estimate the relative migration of the cells, unclosed cell-free areas from ten prints under each condition were excised and weighed on a scale (Mettler AE50). We used 'average gap' (average gap, \%) to quantify the data.

RNA interference (RNAi) experiments. Custom SmartPool ${ }^{\circledR}$ RNAi duplexes (more than four sequences) for AQP3 were chemically synthesized by Dharmacon Research (Lafayette, $\mathrm{CO})$, As described previously (14), HaCaT cells were cultured in complete medium that did not contain antibiotics for 4 days. $\mathrm{HaCaT}$ cells were seeded into a 6 -well plate 1 day prior to transfection and cultured to $60-70 \%$ confluence the following day. For RNAi experiments, $12 \mu 1$ of FuGene6 (Roche Diagnostics, Indianapolis, IN) was diluted in $88 \mu \mathrm{l}$ of DMEM for $5 \mathrm{~min}$ in room temperature. Then, $10 \mu \mathrm{l}$ of $20 \mu \mathrm{M}$ double- 

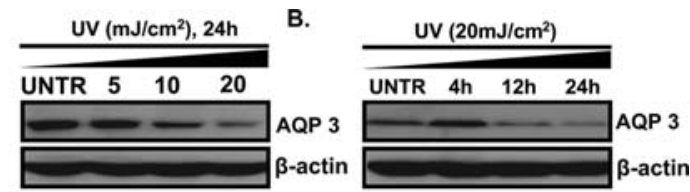

c.
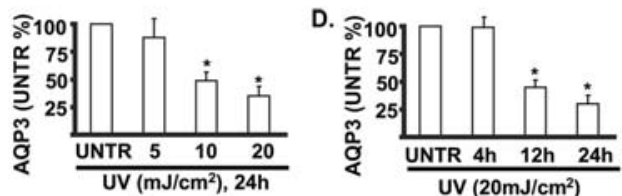

Figure 1. UV induces AQP3 downregulation in a time- and dose-dependent manner in cultured human keratinocytes (HaCaT cells). Cultured skin keratinocytes (HaCaT cells) were treated with different UV doses $(5,10$ and $20 \mathrm{~mJ} / \mathrm{cm}^{2}$ ) and AQP3 expression was analyzed by Western blotting after $24 \mathrm{~h}$ as shown in A. HaCaT cells were also treated with UV $\left(20 \mathrm{~mJ} / \mathrm{cm}^{2}\right)$ and AQP3 was analyzed by Western blotting at different times $(4,12,24 \mathrm{~h})$ as shown in B. $\mathrm{AQP} 3$ expression was quantified in $\mathrm{C}, \mathrm{D}$ respectively, the data represent mean $\pm \mathrm{SE}$ of three independent experiments. ${ }^{*} \mathrm{P}<0.05$ vs untreated (UNTR) group.

stranded RNAs for AQP3 RNAi was mixed with DMEM containing FuGene6 and incubated for $30 \mathrm{~min}$ at room temperature for complex formation. Finally the complex was added to the well containing $2 \mathrm{ml}$ medium with the final AQP3 siRNA concentration of $100 \mathrm{nM}$. AQP3 protein expression was determined by Western blotting, respectively, $48 \mathrm{~h}$ after treatment.

Measurement of water permeability. Water permeability was measured using a well established method as described previously (23). Coverslips with HaCaT cells were mounted in a closed perfusion chamber on the stage of a Zeiss fluorescence microscope. Cells were loaded with calcein and water permeability measurement was performed (see details below). During the off-line analysis of the series, cells were loaded with calcein by a 5-min exposure to $20 \mu \mathrm{M}$ calcein-acetoxymethyl ester (calcein-AM, Invitrogen) in 300 mosM PBS (137 mM NaCl, $0.9 \mathrm{mM} \mathrm{CaCl} 2,0.49 \mathrm{mM} \mathrm{MgCl} 2,2.7 \mathrm{mM}$ $\left.\mathrm{KCl}, 1.5 \mathrm{mM} \mathrm{KH} \mathrm{PO}_{4}, 8.1 \mathrm{mM} \mathrm{Na} \mathrm{HPO}_{4}, \mathrm{pH} 7.35\right)$. The loading of cells with calcein and incubation with drugs was performed at $30^{\circ} \mathrm{C}$ for $10 \mathrm{~min}$. The subsequent water permeability measurements were carried out at $10^{\circ} \mathrm{C}$ to decrease the water diffusion through the lipid bilayer of the plasma membrane. To measure water permeability, cells were perfused with cold $300 \operatorname{mosM}$ PBS for $5 \mathrm{~min}$, then, the perfusate was switched to $150 \operatorname{mosM} \mathrm{PBS}$ at the same temperature $\left(62 \mathrm{mM} \mathrm{NaCl}, 0.9 \mathrm{mM} \mathrm{CaCl}_{2}, 0.49 \mathrm{mM} \mathrm{MgCl}_{2}\right.$, $\left.2.7 \mathrm{mM} \mathrm{KCl}, 1.5 \mathrm{mM} \mathrm{KH} \mathrm{PO}_{4}, 8.1 \mathrm{mM} \mathrm{Na}_{2} \mathrm{HPO}_{4}, \mathrm{pH} 7.35\right)$. Images of the fluorescence intensity of perfused cells were recorded every $2 \mathrm{~min}(0,2,4$ and $6 \mathrm{~min})$ with excitation at $488 \mathrm{~nm}$ and emission at 515-525 nm (green) before and after the solution switch. The series of images were analyzed offline by measuring the time course of the calcein fluorescence in cytoplasmic regions of individual cells, and the fluorescence intensity were quantified by using the BioTek Gen 5 system (BioTek Instruments, Inc. PN). The half-life of deduction of fluorescence intensity is used as a comparable indicator of water permeability. For cell water permeability experiment at least 100 cells in 6 random views were quantified for relative fluorescence intensity.
A.

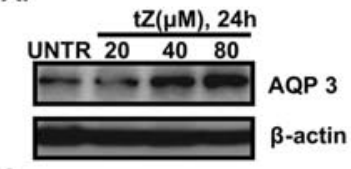

C.

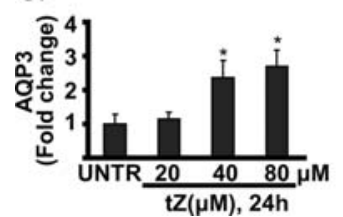

B.

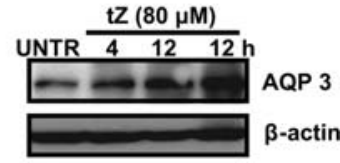

D.

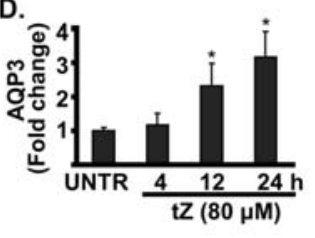

Figure 2. Trans-Zeatin (tZ) upregulates AQP3 in a time- and dose-dependent manner in $\mathrm{HaCaT}$ cells. HaCaT cells were treated with different doses of trans-Zeatin $(20,40,80 \mu \mathrm{M})$ for $24 \mathrm{~h}$ as shown in A and quantified in $\mathrm{C}$ or treated with trans-Zeatin $(80 \mu \mathrm{M})$ for different times $(4,12,24 \mathrm{~h})$ as shown in $\mathrm{B}$ and quantified in D. AQP3 expression was analyzed by Western blotting. The data represent mean \pm SE of three independent experiments ${ }^{*} \mathrm{P}<0.05$ vs untreated (UNTR) group.

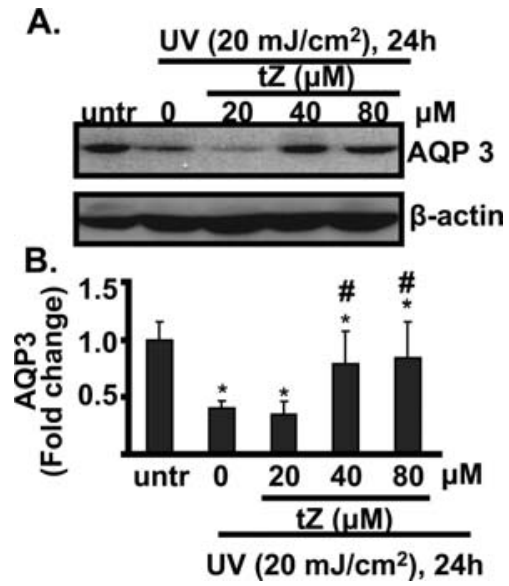

Figure 3. Trans-Zeatin (tZ) attenuates UV induced loss of AQP3 in HaCaT cells. HaCaT cells were pre-treated with different doses of trans-Zeatin (20, $40,80 \mu \mathrm{M}$ ) followed by $20 \mathrm{~mJ} / \mathrm{cm}^{2}$ of UV radiation for $24 \mathrm{~h}$. AQP3 expression was measured by Western blotting (A) and quantified (B). The data represent mean $\pm \mathrm{SE}$ of three independent experiments. ${ }^{*} \mathrm{P}<0.05$ vs untreated (UNTR) group. ${ }^{\#} \mathrm{P}<0.05$ vs UV treated groups.

Statistical analysis. The values in the figures are expressed as the means \pm standard error (SE). The figures in this study are representative of more than 3 different experiments. Statistical analysis of the data between the control and treated groups was performed by a Student's t-test. Values of $\mathrm{p}<0.05$ were considered statistically significant.

\section{Results}

UV downregulates AQP3 in cultured keratinocytes (HaCaT cells). First we examine whether UV radiation affects AQP3 expression. As shown in Fig. 1A, UV-induced AQP3 downregulation was dose-dependent, and $\mathrm{AQP} 3$ expression began to decrease after treated with $10 \mathrm{~mJ} / \mathrm{cm}^{2} \mathrm{UV}$ and was most obvious at $20 \mathrm{~mJ} / \mathrm{cm}^{2} \mathrm{UV}$ treatment. UV-induced downregualtion of AQP3 was also time-dependent (Fig. 1B). AQP3 began to decrease at $12 \mathrm{~h}$ and was most obvious at $24 \mathrm{~h}$ after treated with $20 \mathrm{~mJ} / \mathrm{cm}^{2} \mathrm{UV}$. AQP3 expression is quantified in Fig. 1C and D for Fig. 1A and B, respectively. 
A.
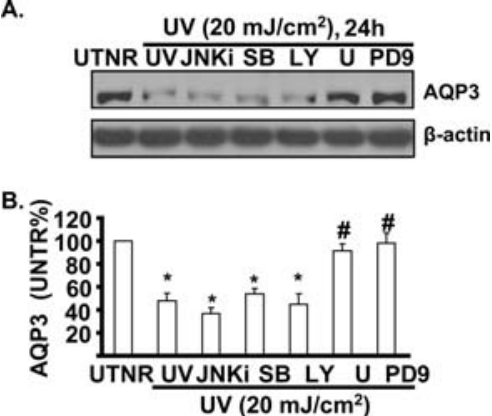

Figure 4. UV-induced AQP3 downregulation is blocked by MEK/ERK inhibitors in $\mathrm{HaCaT}$ cells. HaCaT cells were pretreated with MAPK or PI3K/AKT inhibitors, $10 \mu \mathrm{M}$ of JNKi, $10 \mu \mathrm{M}$ of SB 203580 (SB), $10 \mu \mathrm{M}$ of U0126 (U), $10 \mu \mathrm{M}$ of LY294002 (LY), or $1 \mu \mathrm{M}$ PD98059 (PD9) for $1 \mathrm{~h}$, followed by UV $\left(20 \mathrm{~mJ} / \mathrm{cm}^{2}\right)$ radiation for $24 \mathrm{~h}$. AQP3 expression was analyzed by Western blotting (A) and quantified (B). The data represent mean \pm SE of three independent experiments. ${ }^{*} \mathrm{P}<0.05$ vs untreated (UNTR) group. ${ }^{\#} \mathrm{P}<0.05$ vs UV treated group.

A.

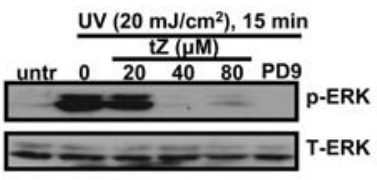

B.

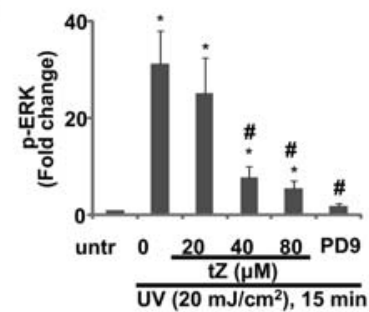

c.

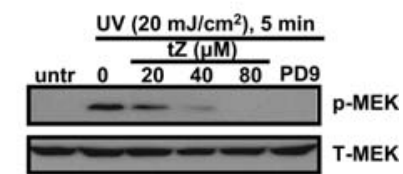

D.

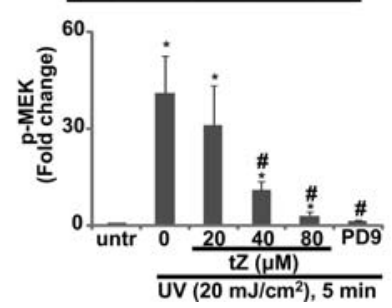

Figure 5. Trans-Zeatin inhibits UV-induced MEK/ERK activation in cultured keratinocytes (HaCaT cells). HaCaT cells were pre-treated with different doses of trans-Zeatin $(20,40$ or $80 \mu \mathrm{M})$ or MEK/ERK inhibitor PD98059 (PD9, $1 \mu \mathrm{M})$ for $2 \mathrm{~h}$, followed by $\mathrm{UV}\left(20 \mathrm{~mJ} / \mathrm{cm}^{2}\right)$ radiation for 5 or $15 \mathrm{~min}$. P-ERK, T-ERK, P-MEK and T-MEK were analyzed by Western blotting (A, B and quantified in $C, D$ respectively). The data represent mean \pm SE of three independent experiments. ${ }^{*} \mathrm{P}<0.05$ vs untreated (UNTR) group. ${ }^{~} \mathrm{P}<0.05$ vs UV treated group.

tZ upregulates AQP3 in cultured keratinocytes (HaCaT cells). Next we examine the potential effects of $t Z$ on AQP3 expression. As shown in Fig. 2A, tZ induces AQP3 upregulation in a dose-dependent manner, and AQP3 expression began to
A.

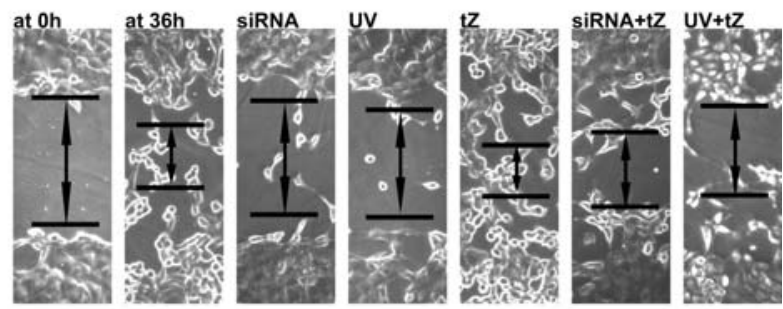

B.
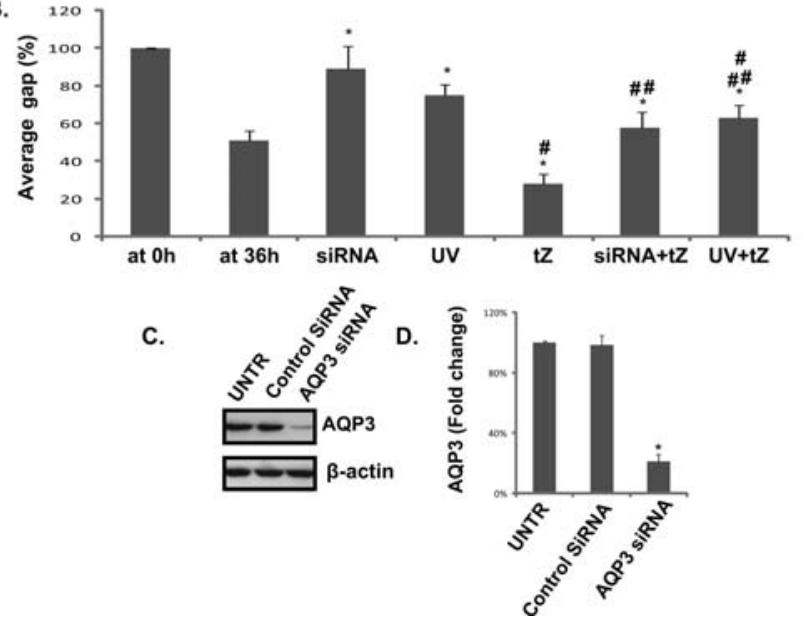

Figure 6. Trans-Zeatin attenuates UV-induced downregulation of wound healing in cultured skin keratinocytes ( $\mathrm{HaCaT}$ cells). $\mathrm{HaCaT}$ cells were treated with AQP3 siRNA for $36 \mathrm{~h}$, in vitro wound healing assay was detected another $36 \mathrm{~h}$ after scratches. HaCaT cells were also pre-treated with or without trans-Zeatin $(80 \mu \mathrm{M})$ followed by UV radiation $\left(20 \mathrm{~mJ} / \mathrm{cm}^{2}\right)$ for $36 \mathrm{~h}$, in vitro wound healing was detected by the methods described before and are shown in A and quantified in B. Ten representative images of the scratched areas under each condition were photographed. Average gap was calculated. Effects of control or AQP3 siRNA on AQP3 expression is shown in $\mathrm{C}$ and AQP3 expression quantified in D. ${ }^{*} \mathrm{P}<0.05$ vs UNTR treated group, ${ }^{*} \mathrm{P}<0.05$ vs UV treated group. ${ }^{\# \#} \mathrm{P}<0.05$ vs siRNA treated group. Magnification 1:100. All experiments were repeated at least three times and similar results were obtained.

increase after $40 \mu \mathrm{M}$ of $\mathrm{tZ}$ treatment. tZ-induced upregulation of AQP3 was also time-dependent (Fig. 2B). AQP3 began to increase at $12 \mathrm{~h}$ and was most obvious at $24 \mathrm{~h}$ after $80 \mu \mathrm{M}$ of tZ treatment. AQP3 expression was quantified in Fig. $2 \mathrm{C}$ and D for Fig. 2A and B, respectively.

$t Z$ attenuates $U V$-induced loss of AQP3 in cultured keratinocytes (HaCaT cells). The above data have clearly shown that UV induces downregulation of AQP3 in HaCaT cells. Next we tested whether $\mathrm{tZ}$ has effects on the loss of AQP3 in UV radiated HaCaT cells. As shown in Fig. 3A and B, tZ attenuates UV-induced AQP3 downregulation in a dosedependent manner.

$U V$-induced AQP3 downregualtion is blocked by MEK/ERK inhibitors in cultured keratinocytes (HaCaT cells). It is well established that MAPK (24) and PI3K (22) activation are involved in a UV-induced photoaging process. Next we tested the potential effects of the activation of these molecular mechanisms in UV-induced AQP3 loss, by using pharmacological inhibitors. As shown in Fig. 4A and B, while JNKi (JNK inhibitor), SB203580 (p38 inhibitor), LY 294002 (PI3K/AKT inhibitor) have almost no effects on UV-induced AQP3 downregualtion, MEK/ERK inhibitors PD98059 and 
A.

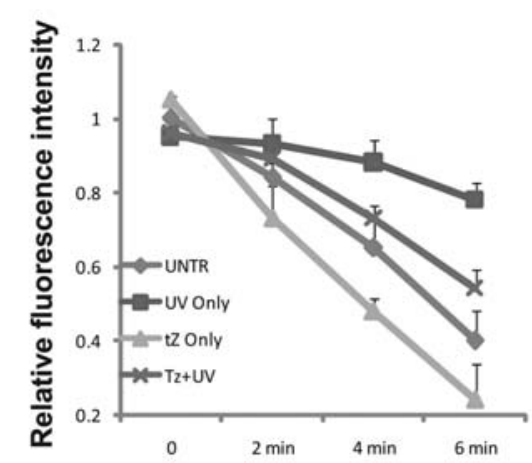

B.

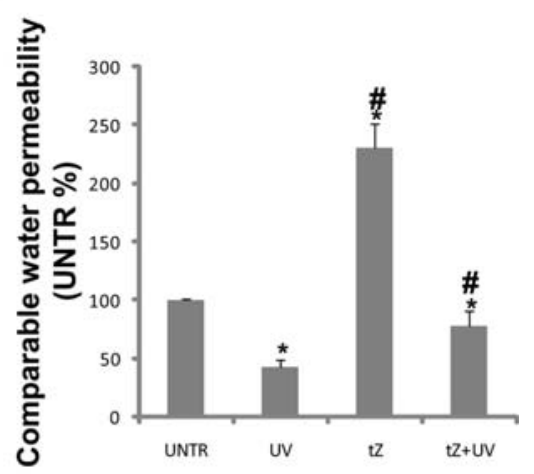

c.

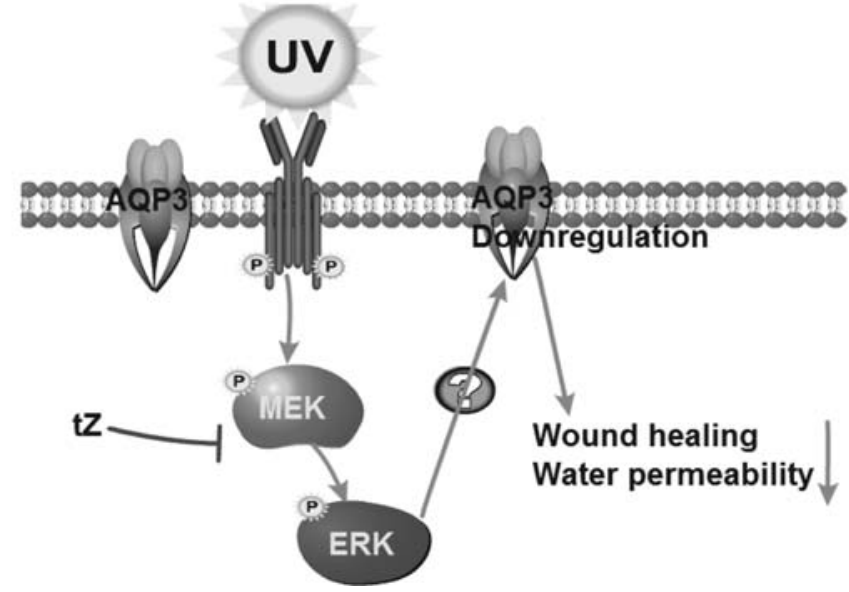

Figure 7. Trans-Zeatin attenuates UV-induced downregulation of water permeability in cultured skin keratinocytes (HaCaT cells). HaCaTs were treated with indicated treatments including UNTR, trans-Zeatin $(80 \mu \mathrm{M}, 24 \mathrm{~h}), \mathrm{UV}$ radiation $\left(20 \mathrm{~mJ} / \mathrm{cm}^{2}, 24 \mathrm{~h}\right)$ and $\mathrm{UV}+$ trans-Zeatin. Water permeability assay was performed using methods described before (A) and comparable water permeability was quantified (B). ${ }^{*} \mathrm{P}<0.05$ vs UNTR treated group, ${ }^{*} \mathrm{P}<0.05$ vs UV treated group. Experiments were repeated at least three times and similar results were obtained. (C) The possible signal pathway involved in this study: UV radiation downregulates AQP3 expression in cultured skin keratinocytes, which is responsible for delayed wound healing and reduced water permeability in $\mathrm{HaCaT}$ cells. MEK/ERK activation is involved in UV-induced AQP3-loss. Trans-Zeatin inhibits UV-induced AQP3 loss and delayed wound healing or reduced water permeability response by inhibiting UV-induced MEK/ERK activation.

U0126 almost block UV-induced AQP3 downregulation in cultured skin keratinocytes (HaCaT cell lines).

$t Z$ inhibits $U V$-induced MEK/ERK activation in cultured keratinocytes (HaCaT cells). Our data above have clearly demonstrated that $\mathrm{tZ}$ inhibits UV-induced AQP3 loss (Fig. 3) and MEK/ERK activation is involved in UV-induced AQP3 loss (Fig. 4). The experiments were performed to further study the effects of $\mathrm{tZ}$ on UV-induced MEK/ERK activation. As shown in Fig. 5. $\mathrm{tZ}$ pretreatment largely inhibited UVinduced MEK phosphorylation in a dose-dependent manner, which could serve as a key mechanism to explain the protective effect of $\mathrm{tZ}$ on UV-induced AQP3 downregulation.

$t Z$ attenuates $U V$-induced downregulation of wound healing in cultured skin keratinocytes (HaCaT cells). Next we tested the functional effects of AQP3 loss in UV radiated skin keratinocytes. As shown in Fig. 6, AQP3 is involved in wound healing response in cultured skin keratinocytes ( $\mathrm{HaCaT}$ cells); siRNA knockdown AQP3 inhibits wound healing response in $\mathrm{HaCaT}$ cells. Our results are consistent with previous works conducted in AQP3 knockout mice $(9,15,25,26)$ and human skin fibroblasts (14). Moreover, loss-of-AQP3 mediated delayed wound healing in UV-radiated skin keratinocytes
(HaCaT cells) was attenuated by $\mathrm{tZ}$ pretreatment. Furthermore, tZ treatment alone induces AQP3 expression (Fig. 2), and enhances wound healing in cultured $\mathrm{HaCaT}$ cells. These results clearly indicate that $\mathrm{tZ}$ inhibits UV-induced delay of wound healing response by reversing AQP3 loss in vitro in cultured skin keratinocytes.

$t Z$ attenuates $U V$-induced downregulation of water permeability in cultured skin keratinocytes (HaCaT cells). We next tested the effects of $\mathrm{tZ}$ on water permeability in cultured skin keratinocytes. As expected, UV radiation, which induces AQP3 loss, decreases water permeability in HaCaT cells (Fig. 7A and B), tZ, which alone enhances AQP3 expression and water per-meability, attenuates UV-induced decreased water permeability (Fig. 7A and B).

\section{Discussion}

The results obtained from this study show that UV radiation, the major cause of skin aging, downregulates the water channel AQP3 in cultured skin keratinocytes (HaCaT cells) (Fig. 1), responsible for some of UV-induced skin aging appearances such as skin dehydration and delayed wound healing (Figs. 6 and 7). Trans-Zeatin (tZ), a potential skin aging preventive 
agent, protects against UV-induced loss of AQP3 (Fig. 3), delayed wound healing and decreased water permeability (Figs. 6 and 7). Investigating the mechanisms we found that MEK/ERK activation is involved in UV-induced downregulation of AQP3 (Fig. 4), and tZ treatment inhibits UVinduced MEK/ERK activation (Fig. 5), which could be a key mechanism for explaining the protective effects of $\mathrm{tZ}$ on UVinduced AQP3 loss.

Changes in lifestyle have caused a significant increase in the amount of UV irradiation people are exposed to, leading to a surge in the incidence of skin photo-aging (5). As these trends are likely to continue in the foreseeable future, development of novel strategies to alleviate UV-induced photoaging are highly desirable goals (5). Recently, botanical antioxidants and natural compounds have gained considerable attention as photoaging preventive agents for human use. Zeatin, purified from zea mays, is a member of the cytokinin group of plant growth factors (19). There is a large amount of information available regarding the activity of zeatin in bacteria, fungi and higher plants (21).

To date, however, there is relatively little attention to the biological effects of zeatin on the human system. In this study, we focused on the mechanisms of tZ's protective effects against UV-induced photoaging. In this study, we found that tZ treatment, which upregulates AQP3 expression (Fig. 2), enhances wound healing and water permeability in keratinocytes (Figs. 6 and 7). Furthermore, tZ treatment, which inhibits UV-induced loss of AQP3 (Fig. 3), attenuates UV-induced delayed wound healing and decreased water permeability (Figs. 6 and 7).

Large studies have provided evidence that UV-induced oxidative stress mediates phosphorylation of protein kinases through a series of cascades, such as mitogen-activated protein kinase (MAPK), PI3K/AKT and activation of transcription factors $(27,28)$. Activation of protein kinases and transcription factors are involved in UV-induced skin cell damage and photoaging. In this study we found that MEK/ERK inhibitors PD98059 and U0126, but not JNK, p38 or AKT inhibitors, inhibit UV-induced AQP3 downregulation (Fig. 4). We conclude that MEK/ERK pathway is involved in UV-induced AQP3 downregulation.

However, the signals involved in tZ's protective effects against UV-induced loss of AQP3 (Fig. 5) has not been studied. Using the specific inhibitors mentioned above, we found that $\mathrm{UV}$-induced MEK/ERK pathway activation, which is responsible for AQP3 downregulation, is also inhibited by $\mathrm{tZ}$ treatment. We conclude that $\mathrm{tZ}$ 's protective effects against $\mathrm{UV}$-induced loss of AQP3 is mediated, at least in part, by an inhibitory effect on UV-induced MEK/ERK activation.

Using specfic siRNA knockdown, we also found that AQP3 is involved in human skin kerationcyte wound healing (Fig. 6). UV radiated keratinocytes, which have less AQP3 protein compared to control cells, display delayed wound healing compared to untreated cell (Fig. 6).

In conclusion, we find that UV downregulates AQP3 in cultured keratinocytes (HaCaT cells), causing delayed wound healing and decreased water permeability in HaCaT cells. $\mathrm{MEK} / \mathrm{ERK}$ pathway is involved in this process. UV-induced AQP3 downregulation, delayed wound healing and decreased water permeability are attenuated by $\mathrm{tZ}$ treatment. Our findings provide an explanation as to the molecular mechanisms of tZ's protective effects against UV-induced photoaging and contribute to potential therapeutic strategies for the treatment and prevention of skin photoaging.

\section{Acknowledgements}

This research was supported in part by grants from the National Natural Science Foundation of China (30271195 and 30671894), Scientific Program of Science and Technology Commission of Shanghai (08JC1403100) and by a grant from NIH (P20 RR016457 from INBRE Program of the National Center for Research Resources).

\section{References}

1. Bruls WA, Slaper H, van der Leun JC and Berrens L: Transmission of human epidermis and stratum corneum as a function of thickness in the ultraviolet and visible wavelengths. Photochem Photobiol 40: 485-494, 1984.

2. Fagot D, Asselineau D and Bernerd F: Matrix metalloproteinase-1 production observed after solar-simulated radiation exposure is assumed by dermal fibroblasts but involves a paracrine activation through epidermal keratinocytes. Photochem Photobiol 79: 499-505, 2004.

3. Xia J, Song X, Bi Z, Chu W and Wan Y: UV-induced NF-кB activation and expression of IL-6 is attenuated by (-)-epigallocatechin-3-gallate in cultured human keratinocytes in vitro. Int $\mathbf{J}$ Mol Med 16: 943-950, 2005.

4. Young AR: Cumulative effects of ultraviolet radiation on the skin: Cancer and photoaging. Semin Dermatol 9: 25-31, 1990.

5. Afaq $\mathrm{F}$ and Mukhtar H: Botanical antioxidants in the prevention of photocarcinogenesis and photoaging. Exp Dermatol 15: 678-684, 2006.

6. Roupe G: [skin of the aging human being]. Lakartidningen 98: 1091-1095, 2001.

7. Weiss JS, Ellis CN, Headington JT and Voorhees JJ: Topical tretinoin in the treatment of aging skin. J Am Acad Dermatol 19: 169-175, 1988.

8. Zelenina $\mathrm{M}$ and Brismar $\mathrm{H}$ : Osmotic water permeability measurements using confocal laser scanning microscopy. Eur Biophys J 29: 165-171, 2000.

9. Hara-Chikuma M and Verkman AS: Aquaporin-3 functions as a glycerol transporter in mammalian skin. Biol Cell 97: 479-486, 2005 .

10. Nakakoshi M, Morishita Y, Usui K, Ohtsuki M and Ishibashi K: Identification of a keratinocarcinoma cell line expressing AQP3. Biol Cell 98: 95-100, 2006.

11. Sasaki S, Ishibashi $\mathrm{K}$ and Marumo F: Aquaporin-2 and -3 : Representatives of two subgroups of the aquaporin family colocalized in the kidney collecting duct. Annu Rev Physiol 60: 199-220, 1998.

12. King LS, Kozono D and Agre P: From structure to disease: The evolving tale of aquaporin biology. Nat Rev Mol Cell Biol 5: 687-698, 2004.

13. Verkman AS: More than just water channels: Unexpected cellular roles of aquaporins. J Cell Sci 118: 3225-3232, 2005.

14. Cao C, Sun Y, Healey S, et al: EGFR-mediated expression of aquaporin-3 is involved in human skin fibroblast migration. Biochem J 400: 225-234, 2006.

15. Ma T, Hara M, Sougrat R, Verbavatz JM and Verkman AS: Impaired stratum corneum hydration in mice lacking epidermal water channel aquaporin-3. J Biol Chem 277: 17147-17153, 2002.

16. Yang B, Ji C, Kang J, Chen W, Bi Z and Wan Y: Trans-Zeatin inhibits UVB-induced matrix metalloproteinase-1 expression via map kinase signaling in human skin fibroblasts. Int J Mol Med 23: 555-560, 2009.

17. Cao C, Wan S, Jiang Q, et al: All-trans retinoic acid attenuates ultraviolet radiation-induced down-regulation of aquaporin-3 and water permeability in human keratinocytes. J Cell Physiol 215: 506-516, 2008.

18. Ji C, Cao C, Lu S, et al: Curcumin attenuates EGF-induced AQP3 up-regulation and cell migration in human ovarian cancer cells. Cancer Chemother Pharmacol 62: 857-865, 2008. 
19. Koenig RL, Morris RO and Polacco JC: tRNA is the source of low-level trans-Zeatin production in methylobacterium spp. J Bacteriol 184: 1832-1842, 2002.

20. Kulaeva ON, Karavaiko NN, Selivankina S, Zemlyachenko YV and Shipilova SV: Receptor of trans-Zeatin involved in transcription activation by cytokinin. FEBS Lett 366: 26-28, 1995.

21. Rattan SI and Sodagam L: Gerontomodulatory and youthpreserving effects of Zeatin on human skin fibroblasts undergoing aging in vitro. Rejuvenation Res 8: 46-57, 2005.

22. Zhang QS, Maddock DA, Chen JP, et al: Cytokine-induced p38 activation feedback regulates the prolonged activation of Akt cell survival pathway initiated by reactive oxygen species in response to UV irradiation in human keratinocytes. Int J Oncol 19: 1057-1061, 2001

23. Cao C, Healey S, Amaral A, et al: ATP-sensitive potassium channel: A novel target for protection against UV-induced human skin cell damage. J Cell Physiol 212: 252-263, 2007.

24. Bode AM and Dong Z: Mitogen-activated protein kinase activation in UV-induced signal transduction. Sci STKE 2003: RE2, 2003.
25. Hara M, Ma T and Verkman AS: Selectively reduced glycerol in skin of aquaporin-3-deficient mice may account for impaired skin hydration, elasticity, and barrier recovery. J Biol Chem 277: 46616-46621, 2002.

26. Hara M and Verkman AS: Glycerol replacement corrects defective skin hydration, elasticity, and barrier function in aquaporin-3-deficient mice. Proc Natl Acad Sci USA 100: 7360-7365, 2003.

27. Peus D, Vasa RA, Beyerle A, Meves A, Krautmacher C and Pittelkow MR: UVB activates ERK $1 / 2$ and p38 signaling pathways via reactive oxygen species in cultured keratinocytes. J Invest Dermatol 112: 751-756, 1999.

28. Katiyar SK, Afaq F, Azizuddin K and Mukhtar H: Inhibition of UVB-induced oxidative stress-mediated phosphorylation of mitogen-activated protein kinase signaling pathways in cultured human epidermal keratinocytes by green tea polyphenol (-)epigallocatechin-3-gallate. Toxicol Appl Pharmacol 176: 110-117, 2001. 